Provided for non-commercial research and education use. Not for reproduction, distribution or commercial use.

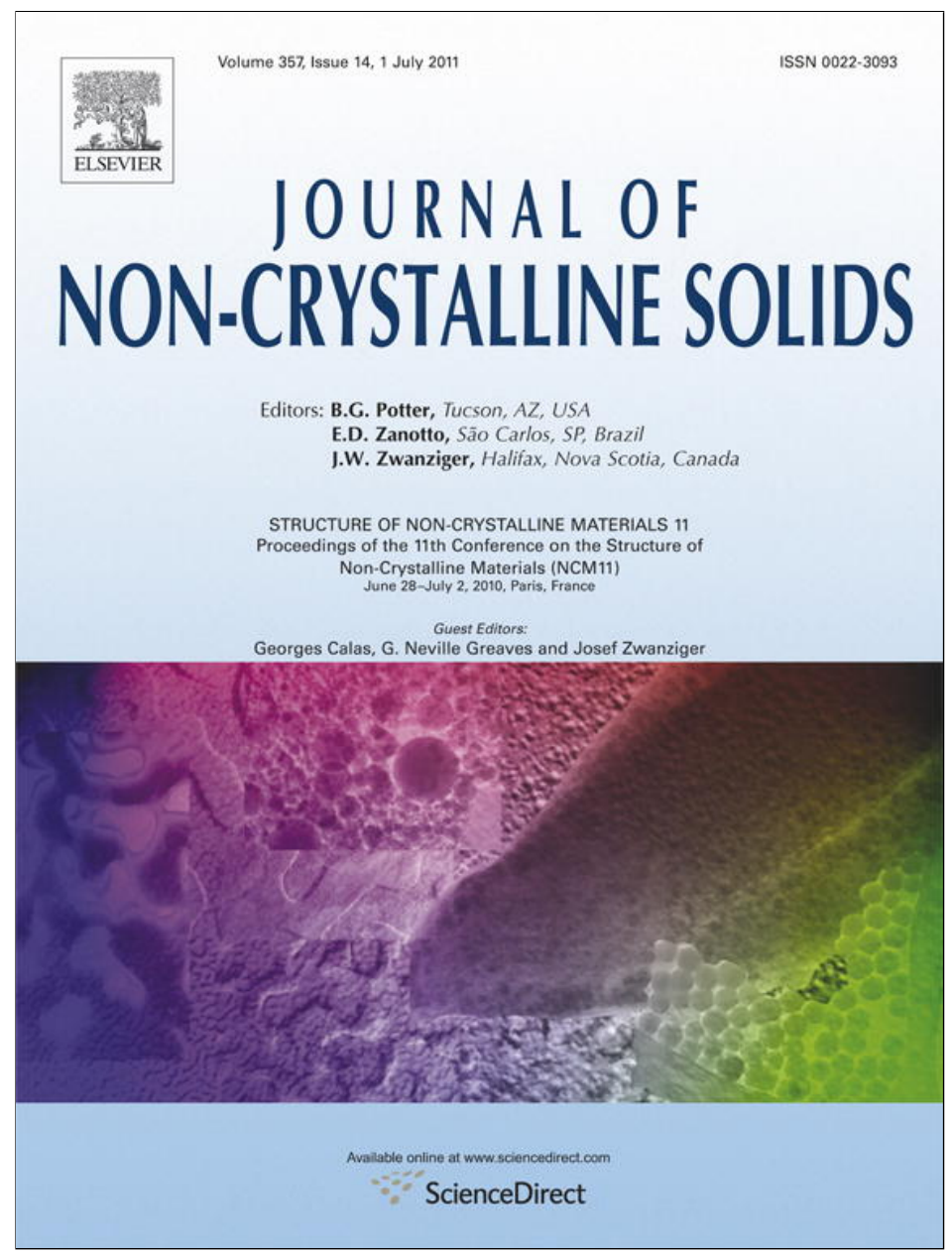

This article appeared in a journal published by Elsevier. The attached copy is furnished to the author for internal non-commercial research and education use, including for instruction at the authors institution and sharing with colleagues.

Other uses, including reproduction and distribution, or selling or licensing copies, or posting to personal, institutional or third party websites are prohibited.

In most cases authors are permitted to post their version of the article (e.g. in Word or Tex form) to their personal website or institutional repository. Authors requiring further information regarding Elsevier's archiving and manuscript policies are encouraged to visit:

http://www.elsevier.com/copyright 


\title{
Vanadium and chromium redox behavior in borosilicate nuclear waste glasses
}

\author{
D.A. McKeown *, I.S. Muller, H. Gan, Z. Feng, Carol Viragh, I.L. Pegg \\ Vitreous State Laboratory, Catholic University of America, 620 Michigan Ave., N.E. Washington, D.C. 20064, USA
}

\section{A R T I C L E I N F O}

\section{Article history:}

Received 16 September 2010

Received in revised form 22 December 2010

Available online 10 February 2011

\section{Keywords:}

XAS;

Redox;

Vanadium;

Chromium;

Glass

\begin{abstract}
A B S T R A C T
X-ray absorption spectroscopy (XAS) was used to characterize vanadium (V) and chromium (Cr) environments in low activity nuclear waste (LAW) glasses synthesized under a variety of redox conditions. $\mathrm{V}_{2} \mathrm{O}_{5}$ was added to the melt to improve sulfur incorporation from the waste; however, at sufficiently high concentrations, $\mathrm{V}$ increased melt foaming, which lowered melt processing rates. Foaming may be reduced by varying the redox conditions of the melt, while small amounts of $\mathrm{Cr}$ are added to reduce melter refractory corrosion. Three parent glasses were studied, where $\mathrm{CO}-\mathrm{CO}_{2}$ mixtures were bubbled through the corresponding melt for increasing time intervals so that a series of redox-adjusted-glasses was synthesized from each parent glass. XAS data indicated that $\mathrm{V}$ and $\mathrm{Cr}$ behaviors are significantly different in these glasses with respect to the cumulative gas bubbling times: $\mathrm{V}^{4+} \mathrm{V}_{\text {total }}$ ranges from 8 to $35 \%$, while $\mathrm{Cr}^{3+} / \mathrm{Cr}_{\text {total }}$ can range from 15 to $100 \%$ and even to population distributions including $\mathrm{Cr}^{2+}$. As Nacontent decreased, $\mathrm{V}$, and especially, $\mathrm{Cr}$ became more reduced, when comparing equivalent glasses within a series. The Na-poor glass series show possible redox coupling between $\mathrm{V}$ and $\mathrm{Cr}$, where $\mathrm{V}^{4+}$ populations increase after initial bubbling, but as bubbling time increases, $\mathrm{V}^{4+}$ populations drop to near the level of the parent glass, while $\mathrm{Cr}$ becomes more reduced to the point of having increasing $\mathrm{Cr}^{2+}$ populations.
\end{abstract}

(c) 2011 Elsevier B.V. All rights reserved.

\section{Introduction}

The role of transition metals, such as vanadium (V) and chromium $(\mathrm{Cr})$, in nuclear waste glasses can be important with respect to crystallization, foaming, and corrosion of materials exposed to the corresponding melts [1]. Depending on the melt composition, many transition metals can increase the tendency for undesirable spinel crystallization upon cooling to the bulk glass waste form or even in the melt itself. Sulfur, originally from the waste, can cause sulfate-salt phase separation and accumulation at the melt surface that can concentrate radio-nuclides as well as increase the rate of corrosion of the materials that are part of the surrounding melter. $\mathrm{V}_{2} \mathrm{O}_{5}$ can be added to the melt to promote sulfur incorporation in the glass, thus reducing or eliminating the formation of a separate sulfate layer. However, at sufficiently high concentrations, $\mathrm{V}_{2} \mathrm{O}_{5}$ can increase melt foaming, which results in slower melt processing. Melt foaming often involves cation reduction and oxygen gas generation, and can be affected by varying redox conditions in the melter. Consequently, there is a need to better understand the redox behavior and foaming characteristics of V-containing low activity nuclear waste (LAW) glasses. In addition, $\mathrm{Cr}$ is present in some waste compositions and also may be added in small amounts to reduce corrosion of the $\mathrm{Cr}$-rich refractory bricks in high-sodium glass melts.

\footnotetext{
* Corresponding author. Tel.: +1 202319 5226; fax: +1 2023194469. E-mail address: davidm@vsl.cua.edu (D.A. McKeown).
}

In this study, $\mathrm{V}$ and $\mathrm{Cr}$ environments in the redox series of three parent glasses are characterized using X-ray absorption spectroscopy (XAS). These parent glasses, Z10-G-60C, Q10-G-136D, and DWV-G-

Table 1

Compositions of the parent glasses used. Measurements were determined from X-ray fluorescence techniques. Uncertainties are less than or equal to $10 \%$ of the reported value. Bold entries are for the elements of interest ( $\mathrm{Cr}$, Fe, and $\mathrm{V}$ ) in this study.

\begin{tabular}{lccc}
\hline Oxide & $\mathrm{Z} 10-\mathrm{G}-60 \mathrm{C}$ & $\mathrm{Q} 10-\mathrm{G}-136 \mathrm{D}$ & $\mathrm{DWV}-\mathrm{G}-123 \mathrm{~B}$ \\
\hline $\mathrm{Al}_{2} \mathrm{O}_{3}$ & 8.71 & 7.21 & 9.46 \\
$\mathrm{~B}_{2} \mathrm{O}_{3}{ }^{\mathrm{a}}$ & 9.90 & 9.80 & 10.90 \\
$\mathrm{CaO}$ & 8.28 & 10.18 & 9.72 \\
$\mathrm{Cr}_{2} \mathbf{O}_{\mathbf{3}}$ & $\mathbf{0 . 8 5}$ & $\mathbf{0 . 4 5}$ & $\mathbf{0 . 2 1}$ \\
$\mathrm{Cs}_{2} \mathrm{O}$ & - & 0.19 & \\
$\mathrm{Fe}_{2} \mathbf{O}_{\mathbf{3}}$ & $\mathbf{0 . 5 8}$ & $\mathbf{0 . 3 7}$ & $\mathbf{1 . 3 3}$ \\
$\mathrm{K}_{2} \mathrm{O}$ & 0.22 & 0.60 & 0.58 \\
$\mathrm{Li}_{2} \mathrm{O}^{\mathrm{a}}$ & 0.00 & 2.49 & 3.51 \\
$\mathrm{MgO}$ & 0.52 & 1.03 & 1.16 \\
$\mathrm{Na}_{2} \mathrm{O}$ & 23.13 & 16.02 & 10.38 \\
$\mathrm{NiO}$ & 0.24 & 0.02 & 0.00 \\
$\mathrm{PbO}_{\mathrm{SiO}}$ & 0.02 & $<0.01$ & 0.00 \\
$\mathrm{TiO}_{2}$ & 36.74 & 41.09 & 42.52 \\
$\mathbf{V}_{\mathbf{2}} \mathbf{O}_{\mathbf{5}}$ & 0.16 & 0.16 & 0.25 \\
$\mathrm{ZnO}_{\mathrm{ZrO}}$ & $\mathbf{2 . 2 7}$ & $\mathbf{2 . 0 0}$ & $\mathbf{1 . 4 2}$ \\
$\mathrm{Cl}_{\mathrm{I}}$ & 3.20 & 3.22 & 3.46 \\
$\mathrm{P}_{2} \mathrm{O}_{5}$ & 3.10 & 3.25 & 3.83 \\
$\mathrm{SO}_{3}$ & 0.31 & 0.03 & 0.01 \\
$\mathrm{SUM}$ & 0.00 & $<0.01$ & 0.03 \\
\hline & 0.39 & 0.18 & 0.08 \\
$\mathrm{Comp}$ & 1.26 & 1.52 & 1.16 \\
\hline
\end{tabular}

a Composition was determined from DCP analyses. 
a

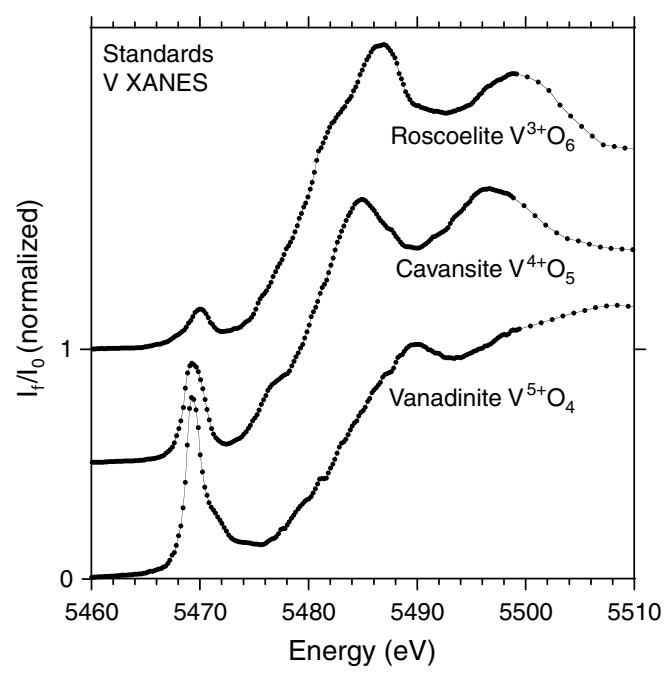

C

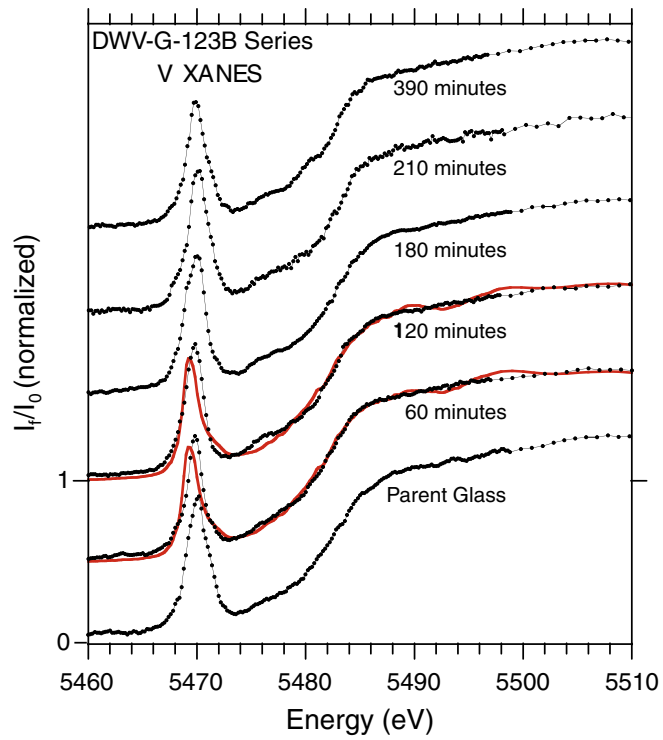

b

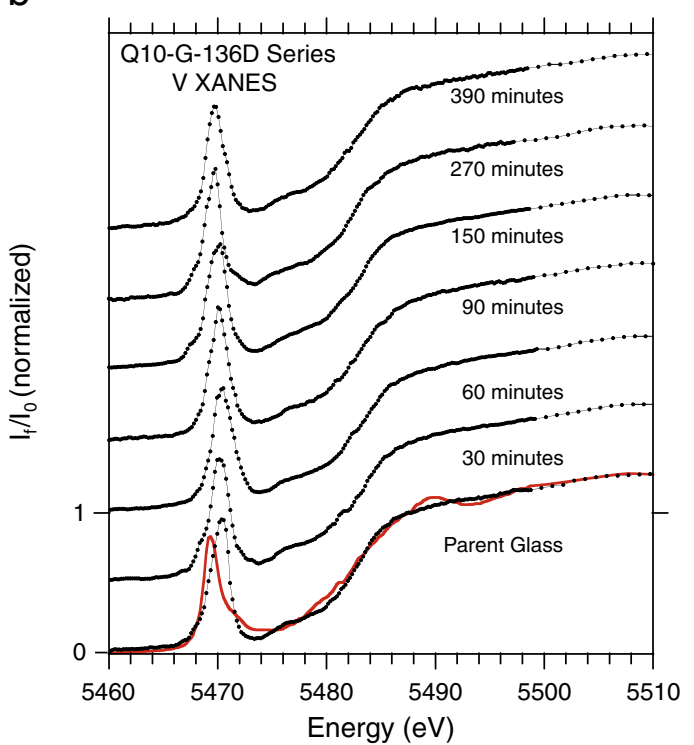

d

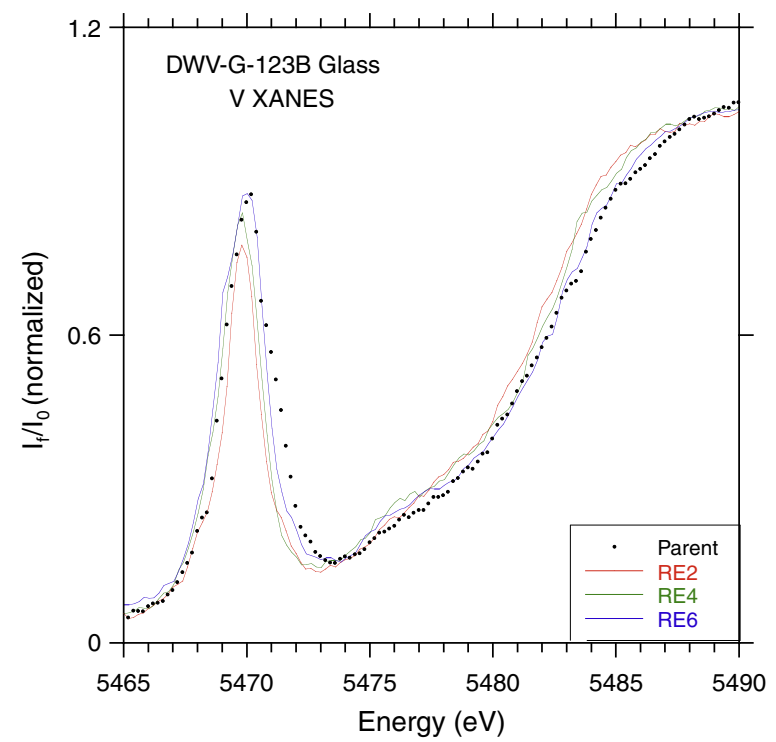

Fig. 1. a. Edge step normalized V K-edge XANES of the valence standards. Plots are offset for clarity. b. Edge step normalized V K-edge XANES data of the Q10-G-136D glass series,

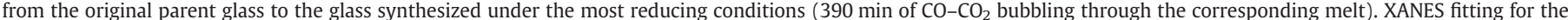
parent glass is indicated in red $\left(0.92 \mathrm{~V}^{5+} \mathrm{O}_{4}+0.08 \mathrm{~V}^{4+} \mathrm{O}_{5}\right)$. c. Edge step normalized V K-edge XANES data of the DWV-G-123B glass series, XANES fitting results are indicated in red. $\mathrm{d}$. V XANES details of four glasses in the DWV-G-123B series, where the valence trends reverse with increasing bubbling times. RE2, RE4, and RE6 glasses correspond to melts having 60, 120 , and 180 min bubbling times, respectively.

123B, have $\mathrm{Li}_{2} \mathrm{O}, \mathrm{MgO}$, and $\mathrm{SiO}_{2}$ concentrations that steadily increase at the expense of $\mathrm{Na}_{2} \mathrm{O}$ and $\mathrm{V}_{2} \mathrm{O}_{5}$ (Table 1). Each parent glass had CO$\mathrm{CO}_{2}$ gas mixtures bubbled through the corresponding melt for increasing time intervals to synthesize a series of redox-adjustedglasses. Due to the proximity of the $\mathrm{Cr}$ K-absorption edge ( $5989 \mathrm{eV}$ ) to the V K-absorption edge $(5465 \mathrm{eV}), \mathrm{V}$ X-ray absorption near-edge spectra (XANES) and extended X-ray absorption spectra (EXAFS) were collected, where the scan energy range was extended to include the $\mathrm{Cr}$ XANES of each sample. Cr EXAFS data were also collected for three glasses from the more Cr-rich Z10-G-60C and Q10-G-136D series, which spanned one glass series from the oxidized parent glass to the most reduced glass where the corresponding melt was exposed to the longest bubbling time.

$\mathrm{V}$ and $\mathrm{Cr}$ environments have been characterized in silicate and borosilicate glasses [2-8]. $\mathrm{V}$ is frequently found within $\mathrm{V}^{5+} \mathrm{O}_{4}$ tetrahedra $[2,3]$, but can have minority $\mathrm{V}^{4+} \mathrm{O}_{5}$ square pyramid populations, when the glass is synthesized under more reducing conditions. $\mathrm{Cr}$ in silicate glasses is typically found within $\mathrm{Cr}^{6+} \mathrm{O}_{4}$ tetrahedra or $\mathrm{Cr}^{3+} \mathrm{O}_{6}$ octahedra [4-6], but can also be seen as $\mathrm{Cr}^{2+}$ [7]. Valence coupling, where electrons are exchanged between these two elements, was observed in silicate glasses synthesized under reducing conditions [8] with $\mathrm{Cr}$ concentrations up to $1.0 \mathrm{wt}$.\%; differences were observed in the V K-edge feature near $5469 \mathrm{eV}$, where the intensity and centroid energy change as functions of $\mathrm{Cr}$ content. In this case, these trends indicate an electron exchange between $\mathrm{V}$ and $\mathrm{Cr}$, where: $\mathrm{V}^{3+}+\mathrm{Cr}^{2+} \rightarrow \mathrm{V}^{2+}+\mathrm{Cr}^{3+}$.

\section{Experimental}

Five crystalline standards were measured to model the possible $\mathrm{V}$ and $\mathrm{Cr}$ environments in the glasses investigated. The $\mathrm{V}$ standards include: vanadinite, $\mathrm{Pb}_{5}\left(\mathrm{VO}_{4}\right) \mathrm{Cl}$, where $\mathrm{V}^{5+}$ is in $\mathrm{VO}_{4}$ tetrahedra [9], cavansite, $\mathrm{Ca}$ 
a

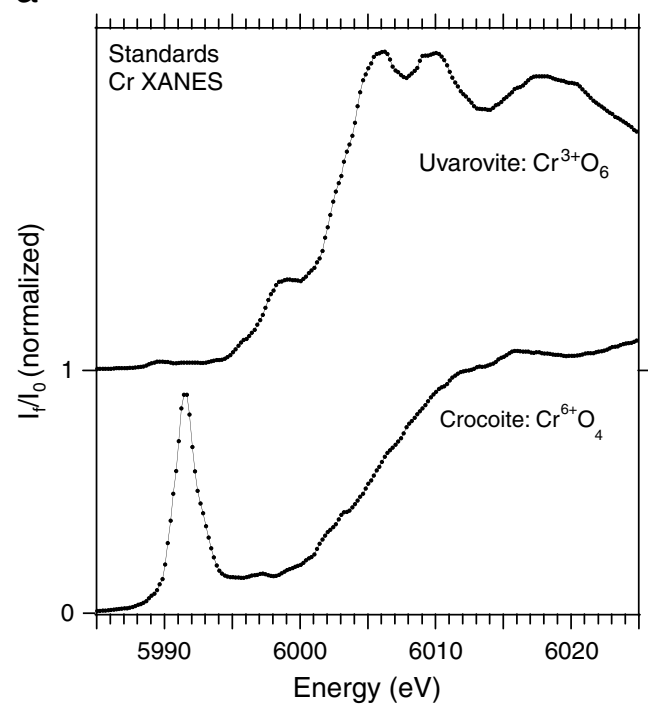

b

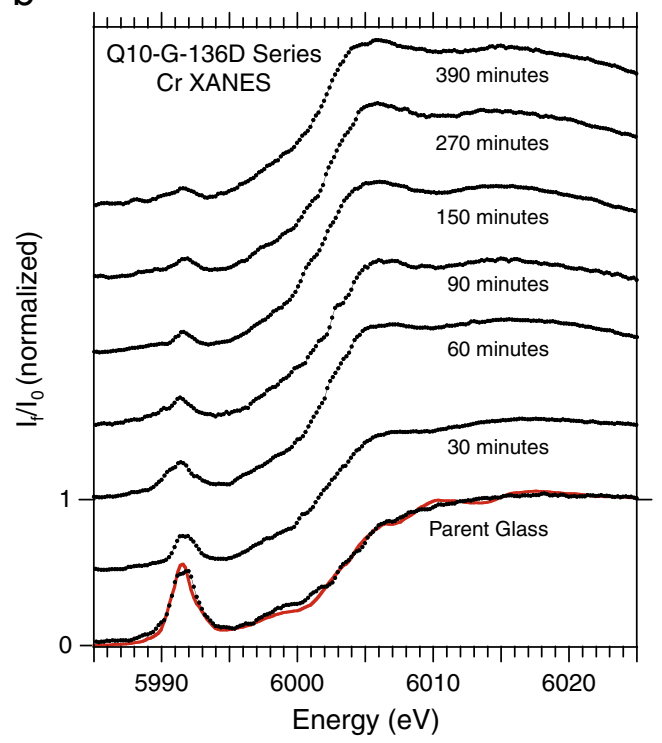

C

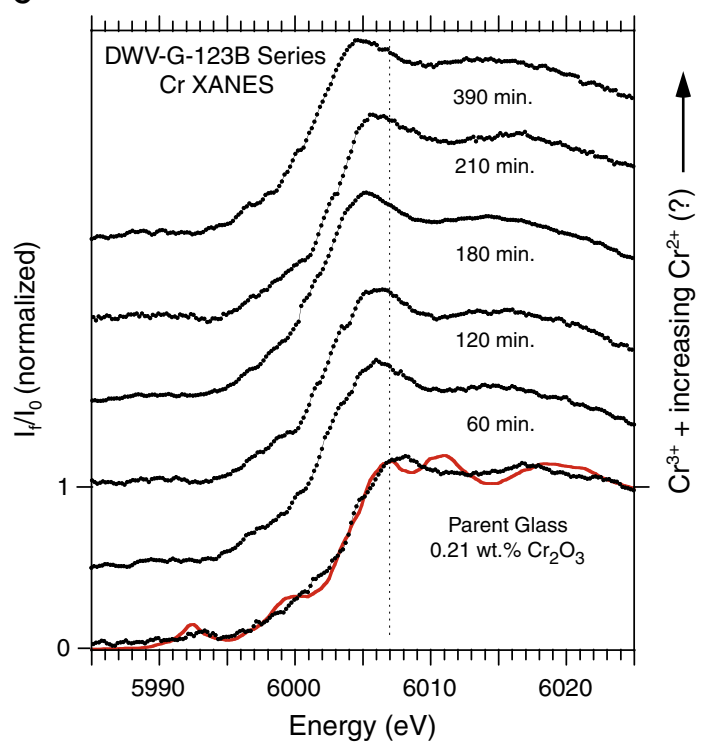

(VO) $\mathrm{Si}_{4} \mathrm{O}_{10} \cdot 4\left(\mathrm{H}_{2} \mathrm{O}\right)$, where $\mathrm{V}^{4+} \mathrm{O}_{5}$ is close to square pyramidal coordination [10], and roscoelite, $\mathrm{K}\left(\mathrm{V}, \mathrm{Mg}, \mathrm{Al}_{2}\right)_{2} \mathrm{AlSi}_{3} \mathrm{O}_{10}(\mathrm{OH})_{2}$, where $\mathrm{V}^{3+}$ is in $\mathrm{VO}_{6}$ octahedra [11]. The $\mathrm{Cr}$ standards include: crocoite $\left(\mathrm{PbCrO}_{4}\right)$, with $\mathrm{Cr}^{6+} \mathrm{O}_{4}$ tetrahedra [12], and uvarovite $\left(\mathrm{Ca}_{3} \mathrm{Cr}_{2} \mathrm{Si}_{3} \mathrm{O}_{12}\right)$, with $\mathrm{Cr}^{3+} \mathrm{O}_{6}$ octahedra [13]. Phase identification of these materials was verified by powder $\mathrm{X}$-ray diffraction.

All glasses studied are based on three parent melter glasses: Z10-G60C, Q10-G-136D, and DVW-G-123B (Table 1) prepared in a slurry fed joule heated pilot vitrification system. About $100 \mathrm{~g}$ of each parent glass was remelted in a Pt crucible at $1150{ }^{\circ} \mathrm{C}$, where a reducing $\mathrm{CO}-\mathrm{CO}_{2}$ mixture was bubbled through the melt to a maximum of $390 \mathrm{~min}$. The $\mathrm{CO}$ and $\mathrm{CO}_{2}$ flow rates were 30 and $20 \mathrm{ml} / \mathrm{min}$ at room temperature, respectively. Melt samples were taken from the crucible in $30 \mathrm{~min}$ or longer bubbling increments so that a series of redox glasses was synthesized: for example, DVW-G-123BRE2 (30 min) to DVW-G123BRE10 (390 min). The DVW-G-123B and Z10-G-60C glasses exposed to longer bubbling times, started with the parent glass melt exposed to 210 min of continuous bubbling, where subsequent melt samples were taken after additional 90 min bubbling increments. Outside of the parent glass and longest bubbling time glass in each series, the intermediate glass samples do not represent true equilibrium conditions. This is reflected in $\mathrm{SO}_{3}$ concentrations that steadily decrease during bubbling. For the DWV$\mathrm{G}-123 \mathrm{~B}$ series, $\mathrm{SO}_{3}$ concentrations are reduced by as much as $70 \%$ of the parent glass composition (Table 1 ).

The X-ray absorption spectra were collected at Beam Line X23B at the National Synchrotron Light Source (NSLS), Brookhaven National Laboratory, where the silicon (111) double crystal monochromator was scanned from 5340 to $6050 \mathrm{eV}$ to include the $\mathrm{V}$ and $\mathrm{Cr}$ K-absorption edges; $\mathrm{Cr}$ XANES and EXAFS scans included an energy range from 5860 to $6514 \mathrm{eV}$. The energy spacing between data points at the edges was $0.2 \mathrm{eV}$. To minimize self-absorption effects, each standard and glass sample was ground and sieved so that a layer of particles approximately one absorption-length thick was placed between two pieces of transparent tape. The flat tape sample was positioned at a $45^{\circ}$ angle with respect to the $2 \mathrm{~mm} \times 2 \mathrm{~mm}$ incident X-ray beam. Fluorescence spectra were gathered for each standard and glass, where the incident $X$-ray beam intensity $\left(I_{0}\right)$ and fluorescence intensity from the sample $\left(\mathrm{I}_{\mathrm{f}}\right)$ were measured by ion chambers flushed with nitrogen $\left(\mathrm{I}_{0}\right)$ and argon $\left(\mathrm{I}_{\mathrm{f}}\right)$. For energy calibration, a $\mathrm{V}$ and $\mathrm{Cr}$ foil reference transmission spectra were measured in parallel with each spectrum collected for a sample, where the edge energy for each foil spectrum was calibrated to the derivative maximum of each edge: $5465 \mathrm{eV}$ for V and $5989 \mathrm{eV}$ for $\mathrm{Cr}$. Due to the limited beam time available, $\mathrm{V}$ XANES and EXAFS as well as Cr XANES were measured for representative glasses that cover the range of redox conditions for each series, while Cr EXAFS were measured for three glasses.

${ }^{57} \mathrm{Fe}$ Mössbauer spectra were recorded for two Na-poor DVW-G123B glass samples to compare with the $\mathrm{Cr}$ and $\mathrm{V}$ valence trends. The experimental set-up used a constant acceleration MS1200 American Magnetics, Inc. spectrometer and a ca. $1.85 \mathrm{GBq}{ }^{57} \mathrm{Co} / \mathrm{Rh}$ source. The samples were mounted in a polyethylene cell. The sample thickness was about $10 \mathrm{mg} / \mathrm{cm}^{2}$ Fe. The line width of the $\alpha$-Fe calibration spectrum at room temperature was $0.29 \mathrm{~mm} / \mathrm{s}$. The data were analyzed by a constrained least-squares fit to Lorentzian-shaped lines. The Mössbauer spectra for the glasses show two superimposed doublets without any magnetic subspectrum. The simplest fitting model was used: two paramagnetic $\mathrm{Fe}^{2+}$ and $\mathrm{Fe}^{3+}$ symmetric doublets with equal line-widths and areas. Based on calibrated

Fig. 2. a. Edge step normalized Cr K-edge XANES of the $\mathrm{Cr}^{6+}$ and $\mathrm{Cr}^{3+}$ standards, crocoite and uvarovite. b. Edge step normalized Cr K-edge XANES data of the Q10-G-136D glass series. XANES fitting for the parent glass is indicated in red $\left(0.66 \mathrm{Cr}^{6+} \mathrm{O}_{4}+0.34 \mathrm{Cr}^{3+} \mathrm{O}_{6}\right)$. c. Edge step normalized $\mathrm{Cr}$ K-edge XANES data of the Na-poor DWV-G-123B glass series, which has the most $\mathrm{Cr}$-reduced glasses in this study. The dashed line at $6007 \mathrm{eV}$ is a guide to view the edge energy shifts, which indicate increasing $\mathrm{Cr}^{2+}$ populations with increasing bubbling time. XANES fitting for the parent glass is indicated in red $\left(0.15 \mathrm{Cr}^{6+} \mathrm{O}_{4}+0.85 \mathrm{Cr}^{3+} \mathrm{O}_{6}\right)$. 
a

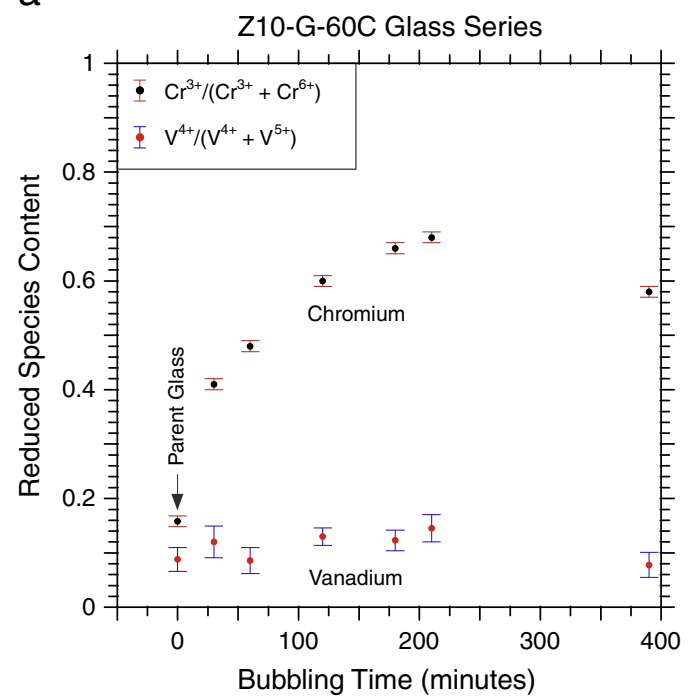

b

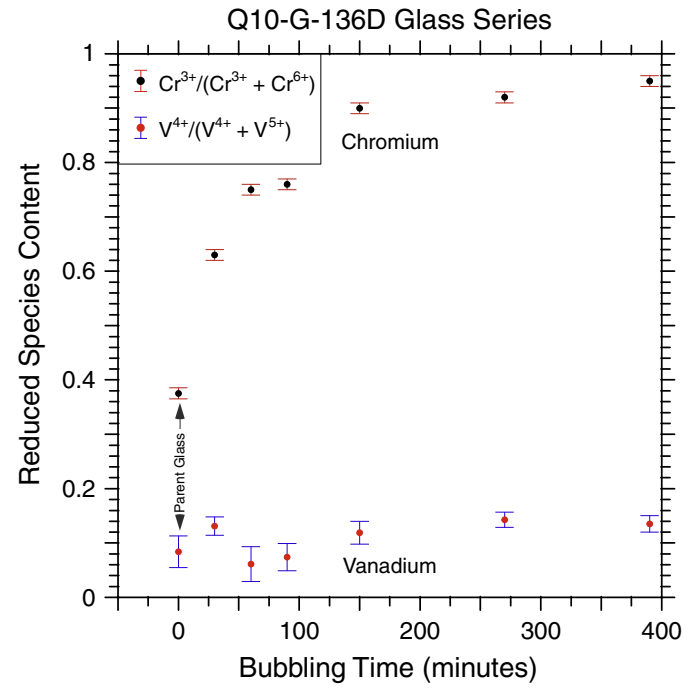

C

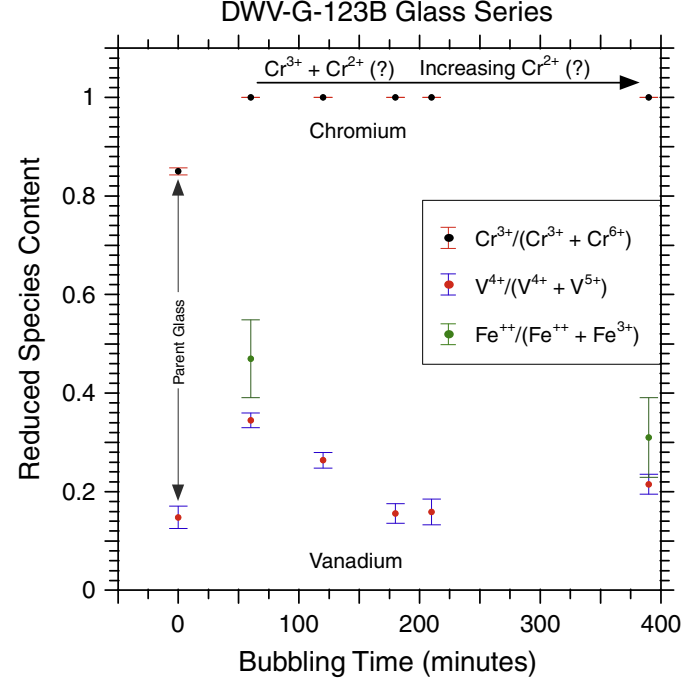

Table 2

First shell $\mathrm{V}-\mathrm{O}$ fitting EXAFS results for the $\mathrm{V}^{5+} \mathrm{O}_{4}$ and $\mathrm{V}^{4+} \mathrm{O}_{5}$ standards, using $\mathrm{s}_{0}^{2}=0.80$ $\mathrm{E}_{0}$ values are from $5465 \mathrm{eV}$. Uncertainties are listed in parentheses.

\begin{tabular}{llllll}
\hline Sample & $\mathrm{r}$-factor & $\mathrm{E}_{0}(\mathrm{eV})$ & $\mathrm{r}(\AA)$ & $\mathrm{n}($ atoms $)$ & $\sigma^{2}\left(\AA^{2}\right)$ \\
\hline Vanadinite & 0.057 & $9.1(2.1)$ & $1.73(0.02)$ & $3.9(0.7)$ & $0.0006(0.0025)$ \\
$\quad$ Actual [9] & & & 1.70 & 4.0 & \\
Cavansite & 0.046 & $6.7(5.1)$ & & & \\
$\quad$ Fit & & & $1.62(0.04)$ & $1.1(0.7)$ & $0.0010(0.0011)^{\mathrm{a}}$ \\
$\quad$ Actual [10] & & & 1.60 & 1.0 & \\
Fit & & $1.96(0.04)$ & $4.0(0.9)$ & $0.0010(0.0011)^{\mathrm{a}}$ \\
$\quad$ Actual [10] & & 1.98 & 4.0 & \\
\hline a $\sigma^{2}$ constrained to be the same for both nearest neighbor contributions.
\end{tabular}

glasses in the range of $3 \%$ to $60 \% \mathrm{Fe}^{++} / \mathrm{Fe}_{\text {total }}$ and as previously verified in silicate melts [14], there is no significant difference between the recoil-free fractions of $\mathrm{Fe}^{2+}$ and $\mathrm{Fe}^{3+}$ and the redox ratio was calculated from the areas of the corresponding doublets.

\section{Data analysis}

X-ray absorption data for all samples were processed and analyzed using program IFEFFIT [15] (Figs. 1-6). The X-ray absorption spectrum for each sample is an average of at least two data sets that were initially processed using standard pre-edge background subtraction, edge-step normalization, and energy calibration procedures. Direct comparisons could then be made among XANES data from all samples to an energy accuracy of $\pm 0.2 \mathrm{eV}$ (Figs. 1-2). To produce the EXAFS data for analysis, a spline function was fit to and then subtracted from the edge-step normalized XAS data, from approximately 35 to $500 \mathrm{eV}$ past the absorption edge. Energy values in $\mathrm{eV}$ were converted to $\mathrm{k}\left(\AA^{-1}\right)$ [16], where the resulting $\chi(\mathrm{k})$ data were $\mathrm{k}^{2}$-weighted (Figs. 4a, 5a, c, e, 6a, and c bottom). The $\mathrm{k}^{2} \chi(\mathrm{k})$ data for the standards were then Fourier transformed over the $2.0 \leq \mathrm{k} \leq 10.5 \AA^{-1}$ range using $0.5 \AA^{-1}$ Hanning windows on the upper and lower limits of the data to minimize termination artifacts in the resulting partial radial distribution function (RDF) (Figs. 4b, 5b, and 6b). Damping of EXAFS oscillations for most glasses is so pronounced at higher k-ranges that the $\mathrm{k}^{2} \chi(\mathrm{k})$ data were truncated at $9.5 \AA^{-1}$ due to the lack of any appreciable EXAFS signal beyond this point (Fig. 5a and c). Peaks in the RDFs correspond to shells of atoms surrounding $\mathrm{V}$ or $\mathrm{Cr}$, where average bond distance $(r(\AA))$, coordination number ( $n$ (atoms)), and disorder (Debye-Waller factor or $\sigma^{2}\left(\AA^{2}\right)$ ) for each atomic shell were obtained from EXAFS fitting procedures $[15,16]$. The position of each peak in the RDF is phase-shifted to lower $r$ by 0.2 to $0.3 \AA$ with respect to the actual bond distance. The standards EXAFS data were processed first to determine $s_{0}^{2}$ and $E_{0}$ values, while $r$ and $n$ were constrained to the known values from the crystal structure. Once a reasonable $s_{0}^{2}$ value was determined, this variable was constrained while $\mathrm{r}, \mathrm{n}$, and $\sigma^{2}$ were varied for the standards and glass data.

To determine the $\mathrm{V}$ and $\mathrm{Cr}$ valence distributions for each glass, XANES data were fit using the corresponding $V$ XANES for vanadinite and cavansite (Fig. 1b and c) and $\mathrm{Cr}$ XANES for crocoite and uvarovite (Fig. $2 \mathrm{~b}$ and $\mathrm{c}$ ). XANES for the standards include rapidly varying interference features caused by the surrounding crystal structure that may not be seen in the XANES for the glasses, even though the glasses may have the same valence and nearest-neighbor environment as the standard. These differences can cause issues with fitting certain XANES features for a glass, producing added uncertainties to the final fitting results. This is especially true for $\mathrm{V}$ in this study (such as the misfit of the $5470 \mathrm{eV}$ feature, Fig. 1b and c), where valence uncertainties determined

Fig. 3. a. $\mathrm{CO}-\mathrm{CO}_{2}$ bubbling time versus $\mathrm{V}$ and $\mathrm{Cr}$ reduction for the $\mathrm{Z10}-\mathrm{G}-60 \mathrm{C}$ glasses, from XANES fitting analyses; $\mathrm{Na}_{2} \mathrm{O}$ content is $23.13 \mathrm{wt}$.\% Uncertainties are shown as error bars. b. $\mathrm{CO}-\mathrm{CO}_{2}$ bubbling versus $\mathrm{V}$ and $\mathrm{Cr}$ reduction for the Q10-G-136D glasses, from XANES fitting analyses; $\mathrm{Na}_{2} \mathrm{O}$ content is 16.02 wt.\%. c. $\mathrm{CO}-\mathrm{CO}_{2}$ bubbling versus $\mathrm{V}$ (XANES analyses), $\mathrm{Cr}$ (XANES analyses), and Fe (Mössbauer analyses) reduction for the DWV-G-123B glasses; $\mathrm{Na}_{2} \mathrm{O}$ content is 10.38 wt \% 
a

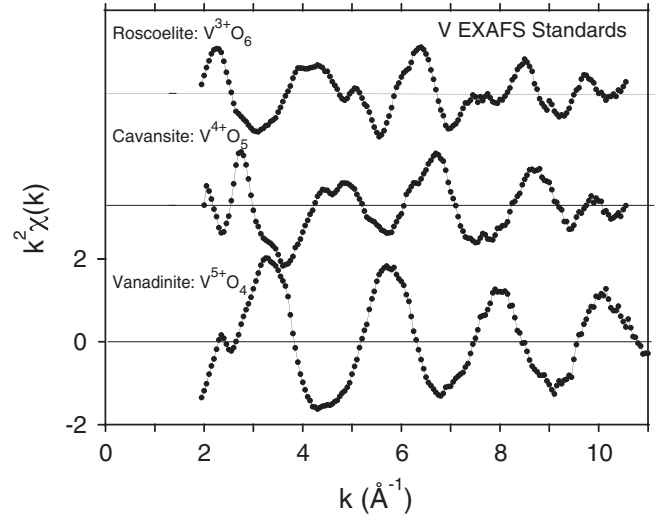

b

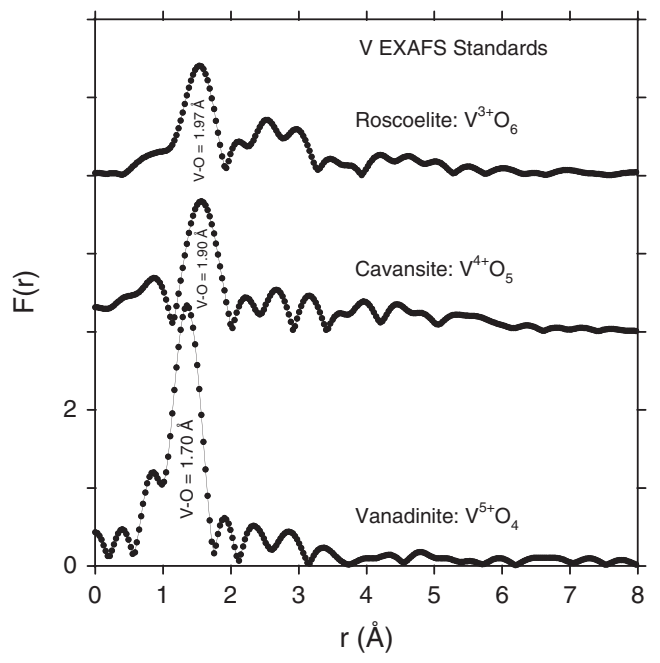

Fig. 4. a. $\mathrm{V} \mathrm{k}^{2} \chi(\mathrm{k})$ EXAFS data for the three standards. Plots are offset for clarity. b. V partial RDF data for the three standards. Plots are offset for clarity.

by IFEFFIT may be smaller than actual. An uncertainty upper limit for the $V$ determinations can be obtained by direct observations from the data: XANES differences between DWV-G-123BRE2 and RE4 are clearly seen (Fig. 1d). These differences represent an $8.2 \% \mathrm{~V}^{4+} / \mathrm{V}_{\text {total }}$ difference according to IFEFFIT (Fig. 3c). The upper limit uncertainty for each $\mathrm{V}$ XANES valence determination in this study can be defined as $<4.1 \%$. (or half of the above difference for each point) The uncertainties calculated by IFEFFIT can be a lower uncertainty limit, which ranges from 1.4 to $3.2 \% \mathrm{~V}^{4+} / \mathrm{V}_{\text {total. }}$. Valence determinations from the XANES fitting results for each glass series are plotted in Fig. 3a-c.

The V EXAFS analysis for vanadinite and cavansite (Table 2) produced $\mathrm{r}, \mathrm{n}$, and $\sigma^{2}$ values that are in reasonable agreement with respect to the $V$ environments determined from the crystal structure refinements $[9,10]$. For some of the analyses, it was necessary to constrain $\mathrm{n}$ or $\sigma^{2}$ to obtain physically meaningful values. It was also necessary to vary $E_{0}$ to best fit the nearest-neighbor RDF peak positions that slightly affects the corresponding $r$-value determined from the fitting. The resulting $E_{0}$ values show a relationship with the $V$ valence range of the samples analyzed (Tables 2-4), where the most oxidized sample, vanadinite has $\mathrm{E}_{0}=5474.1 \mathrm{eV}$, while more reduced samples, such as cavansite and DWV-G-123B reduced glasses have lower $\mathrm{E}_{0}$ values from 2.4 to $11.9 \mathrm{eV}$ below that of vanadinite.

The $\mathrm{Cr}$ EXAFS analysis started with fitting the crocoite and uvarovite data (Table 5). $\mathrm{E}_{0}$ is also sensitive to cation valence, and was determined to be $6002.4 \mathrm{eV}$ for crocoite $\left(\mathrm{Cr}^{6+}\right)$ and $5988.1 \mathrm{eV}$ for uvarovite $\left(\mathrm{Cr}^{3+}\right)$. A two-site model provided the best fit for the three glasses measured (Table 6), which used first shell theory from
IFEFFIT to generate paths for a tetrahedral $\mathrm{CrO}_{4}$ cluster, similar to that in crocoite, and for an octahedral $\mathrm{CrO}_{6}$ cluster, similar to that in uvarovite. The fitting procedure for the glass data constrained the $n$ values for the tetrahedral and octahedral sites to 4.0 and 6.0, respectively, while fractional scale factors: a for the tetrahedral contribution and b for the octahedral contribution were varied, where $\mathbf{a}+\mathbf{b}=1$ for each glass. $\mathrm{r}$ and $\sigma^{2}$ for each site were varied individually. Due to the lower $\mathrm{Cr}_{2} \mathrm{O}_{3}$ concentration for Q10-G-136D glass (Table 1) and the poorer signal-to-noise Cr EXAFS data for this sample (Fig. 6a), it was necessary to constrain both $\sigma^{2}$ parameters. For both sites, it was found that $E_{0}=6002.4 \mathrm{eV}$ provided better fits to the experimental data for the glasses. As a check, this model was applied to the crocoite and uvarovite standards data and the fitting determined a to be statistically zero for uvarovite and $\mathbf{b}$ statistically zero for crocoite.

\section{Discussion}

\subsection{Vanadium XANES}

The $\mathrm{V}$ edges for all glasses studied can be roughly described as a linear combination of the vanadinite $\left(\mathrm{V}^{5+} \mathrm{O}_{4}\right)$ and cavansite $\left(\mathrm{V}^{4+} \mathrm{O}_{5}\right)$ XANES (Fig. 1a-c). The edge changes between these two standards can describe the overall V XANES changes for the glasses; however, crystal structure interference effects in the XANES of the standards cause problems especially with closely fitting the narrow feature near $5470 \mathrm{eV}$ for the glasses. Vanadinite and cavansite have narrower nonGaussian shaped $5470 \mathrm{eV}$ features; the equivalent feature for the glasses is in general more Gaussian shaped. The remainder of the edge (up to $5495 \mathrm{eV}$ ) is better described by the fitting (Fig. 1b and c). These errors in fitting are variable for the glasses where the shape and area of $5470 \mathrm{eV}$ feature can change along with the shape of the edge near $5485 \mathrm{eV}$.

XANES fitting results indicate that the $V$ valence distributions in the more Na-rich Z10-G-60C and Q10-G-136D glasses are dominated by $\mathrm{V}^{5+}$, with 6 to $15 \% \mathrm{~V}^{4+}$ (Figs. $1 \mathrm{~b}, 3 \mathrm{a}$ and b). The $\mathrm{V}^{4+}$ fraction in the Z10-G-60C and Q10-G-136D series is basically independent of bubbling time from the parent glass where valence changes are mostly within the uncertainties determined from the fitting procedure (Fig. 3a and b).

The Na-poor DWV-G-123B glasses are generally the most reduced and show the widest $\mathrm{V}$ valence variation: from 14 to $33 \% \mathrm{~V}^{4+}$ with the rest being $\mathrm{V}^{5+}$ (Figs. 1c, d, and 3c). The XANES show a maximum amount of $\mathrm{V}$ reduction for the $60 \mathrm{~min}$ bubbling glass (DWV-G123BRE2), where the narrow $5470 \mathrm{eV}$ feature has diminished intensity while the main edge has a slightly enhanced shoulder near $5485 \mathrm{eV}$ compared with the parent glass. The trends reverse for the glasses with longer bubbling times RE4 (120 min) and RE6 (180 min) (Fig. 1d). Glasses exposed to longer bubbling times become more oxidized, and approach the valence distribution of the parent glass (Figs. 1c and 3c).

\subsection{Chromium XANES}

$\mathrm{Cr}$ XANES fitting for the glasses used linear combinations of the crocoite $\left(\mathrm{Cr}^{6+} \mathrm{O}_{4}\right)$ and uvarovite $\left(\mathrm{Cr}^{3+} \mathrm{O}_{6}\right)$ XANES (Fig. 2a). The $\mathrm{Z10}-$ G-60C and Q10-G-136D glass data can be described as weighted sums of the XANES for crocoite and uvarovite. The fitting results indicate that $\mathrm{Cr}$ valence distributions become more reduced as bubbling time increases (Figs. 2b, c, 3a, b, and c). $\mathrm{Cr}$ is the most reduced in the DWV$\mathrm{G}-123 \mathrm{~B}$ series, where the parent glass has $85 \% \mathrm{Cr}^{3+} /\left(\mathrm{Cr}^{3+}+\mathrm{Cr}^{6+}\right)$ (Fig. 3c). XANES of any DWV-G-123B glasses where the melts were exposed to bubbling show no evidence of the $\mathrm{Cr}^{6+} 5992 \mathrm{eV}$ feature. Glasses with longer bubbling times than DWV-G-123BRE2 (60 min bubbling and $\left.\mathrm{Cr}^{3+} /\left(\mathrm{Cr}^{3+}+\mathrm{Cr}^{6+}\right)=1\right)$ have edge maxima that continue to shift to lower energies while a shoulder appears near the bottom of the 
a

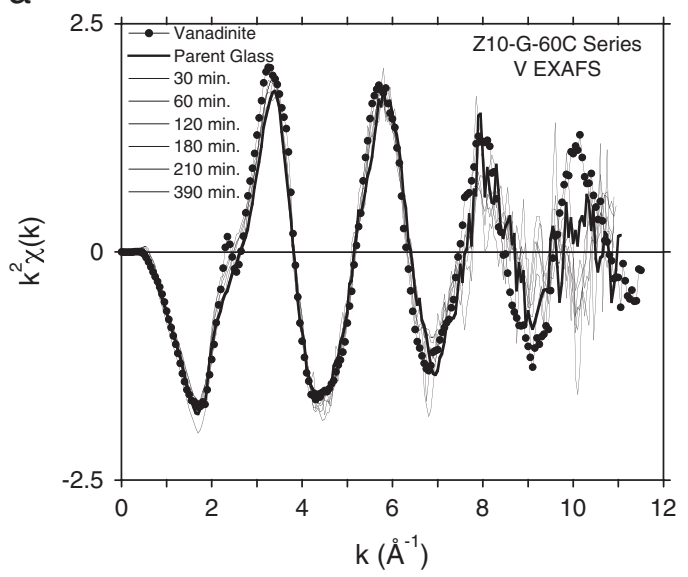

C

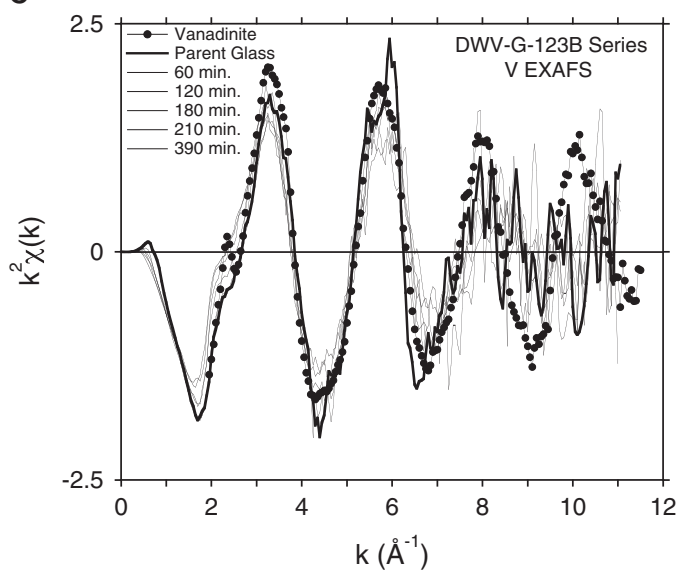

b

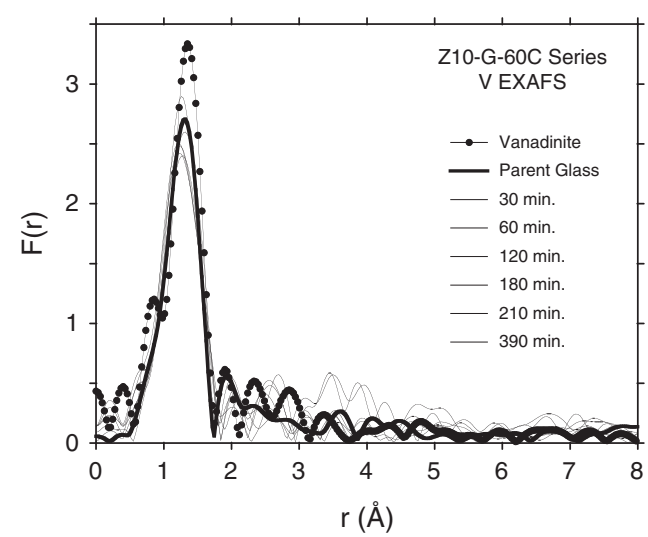

d

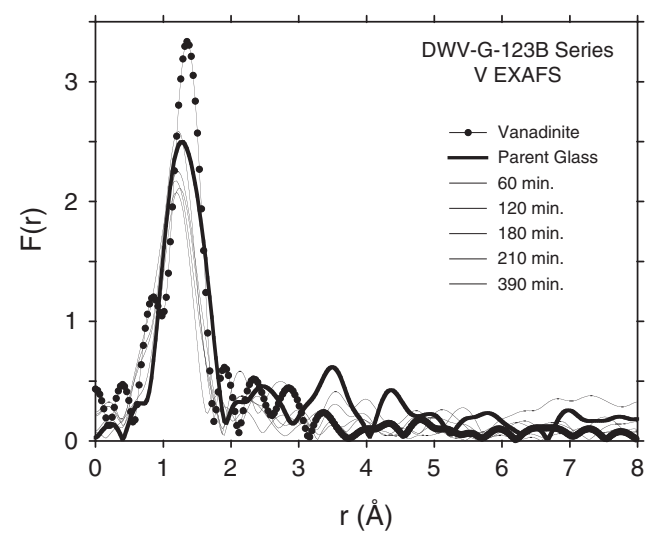

e

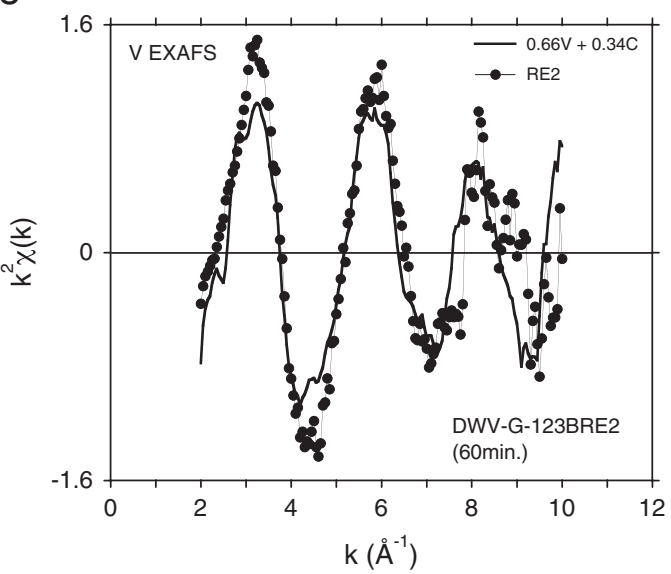

Fig. 5. a. $\mathrm{V} \mathrm{k}^{2} \chi(\mathrm{k})$ EXAFS data for the $\mathrm{V}^{5+} \mathrm{O}_{4}$ standard vanadinite and the $\mathrm{Z10}-\mathrm{G}-60 \mathrm{C}$ glass series (most oxidized). b. V partial RDF data for vanadinite and the Z10-G-60C glass series (most oxidized). c. V k ${ }^{2} \chi(\mathrm{k})$ EXAFS data for vanadinite and the DWV-G-123B glass series (most reduced). d. V partial RDF data for vanadinite and the DWV-G-123B glass series (most reduced). e. $\mathrm{V} \mathrm{k}^{2} \chi(\mathrm{k})$ data for DWV-G-123BRE2 glass (points and line) and a weighted sum of the vanadinite and cavansite $\mathrm{k}^{2} \chi(\mathrm{k})$ data (line) according to the XANES fitting results (see Table 4).

edge (Fig. 2c). This trend likely indicates significant $\mathrm{Cr}^{2+}$ populations in the more reduced DWV-G-123B glasses. Similar Cr XANES trends were reported by Berry et al. (Figs. 2a and $4 a$ in [7]) for $0.5 \mathrm{wt} . \% \mathrm{Cr}_{2} \mathrm{O}_{3}$ in aluminosilicate glasses synthesized under controlled atmospheres, where $\log \left(\mathrm{fO}_{2}\right)$ ranged from -2 to $-7 ; \mathrm{Cr}^{2+} / \mathrm{Cr}_{\text {total }}>10 \%$ was found in glasses synthesized under more reducing conditions, where $\log \left(\mathrm{fO}_{2}\right)<-5$. For the $\mathrm{CO}-\mathrm{CO}_{2}$ bubbled glasses investigated here the estimated $\log \left(\mathrm{fO}_{2}\right)$ could be as small as -8 , or well within the range of having measurable amounts of $\mathrm{Cr}^{2+}$ in silicate glasses [7].

\subsection{Vanadium and chromium XANES trends versus glass chemistry}

Overall, XANES fitting analyses for the glasses indicate that as $\mathrm{Na}_{2} \mathrm{O}$ content decreases, both $\mathrm{V}$ and $\mathrm{Cr}$ are, on average, more reduced (Fig. 3a-c). This is consistent with glass basicity arguments [7], where glasses that are less polymerized or have more network modifying cations such as $\mathrm{Na}$, stabilize higher cation oxidation states. The behaviors of $\mathrm{V}$ and $\mathrm{Cr}$ valence distributions in the glasses with respect to the elapsed bubbling times is significantly different (Q10-G-136D 
Table 3

First shell V-O fitting EXAFS results for the Z10-G-60C glasses, from most oxidizing to most reducing synthesis conditions. Reduced vanadium percentages were determined from XANES analyses. Uncertainties are listed in parentheses. Conventions in Table 2 are followed. + indicates bubbling was done for 210 min continuously with a new parent glass sample.

\begin{tabular}{|c|c|c|c|c|c|c|}
\hline Sample & $\mathrm{V}^{4+} /\left(\mathrm{V}^{5+} \pm \mathrm{V}^{4+}\right)$ & $\mathrm{r}$-factor & $\mathrm{E}_{0}(\mathrm{eV})$ & $r(\AA)$ & $\mathrm{n}$ (atoms) & $\sigma^{2}\left(\AA^{2}\right)$ \\
\hline Parent glass & $9(2) \%$ & 0.038 & $4.4(6.0)$ & $1.68(0.04)$ & $4.0(1.1)$ & $0.0023(0.0034)$ \\
\hline RE1 (30 min) & $12(3)$ & 0.035 & $4.9(5.5)$ & $1.69(0.04)$ & $4.1(1.1)$ & $0.0024(0.0034)$ \\
\hline RE2 (60 min) & $9(2)$ & 0.021 & $3.0(3.2)$ & $1.67(0.03)$ & $4.0(0.6)$ & $0.0027(0.0022)$ \\
\hline RE4 (120 min) & $13(2)$ & 0.020 & $3.0(3.1)$ & $1.68(0.03)$ & $4.1(0.6)$ & $0.0030(0.0022)$ \\
\hline RE6 (180 min) & $12(2)$ & 0.016 & $4.1(2.8)$ & $1.68(0.02)$ & $3.9(0.5)$ & $0.0027(0.0020)$ \\
\hline RE7 (210 min) & $14(3)$ & 0.023 & $3.8(3.2)$ & $1.68(0.03)$ & $4.1(0.6)$ & $0.0025(0.0022)$ \\
\hline RE8 $(210 \mathrm{~min})+$ & $10(2)$ & 0.018 & $3.7(3.0)$ & $1.68(0.02)$ & $4.0(0.6)$ & $0.0028(0.0021)$ \\
\hline RE10 (390 min) & $8(2)$ & 0.014 & $3.5(2.6)$ & $1.68(0.02)$ & $4.2(0.5)$ & $0.0025(0.0017)$ \\
\hline
\end{tabular}

glasses, Figs. 1b and 2b). In general, the V XANES features do not change significantly from the oxidized parent glass to the most reduced glasses, as observed earlier for borosilicate glasses [2]. However, Cr XANES show large variations as these melts are exposed to longer bubbling times (Fig. 3a-c). The reduced species contents for $\mathrm{V}$ and $\mathrm{Cr}$ are closest to each other in the Na-rich parent glass (Z10-G60C) (Fig. 3a), and then diverge to where $\mathrm{Cr}^{3+} / \mathrm{Cr}_{\text {total }}$ is over four times larger than $\mathrm{V}^{4+} / \mathrm{V}_{\text {total }}$ in the Na-poor DWV-G-123B glass (Fig. 3c).

\subsection{Vanadium EXAFS}

The V EXAFS data and fitting results for the standards vanadinite and cavansite, are similar to those presented earlier [2] (Fig. 4a and b). The $\mathrm{k}^{2} \chi(\mathrm{k})$ data for the Z10-G-60C and Q10-G-136D series have slightly smaller amplitudes, and are more damped at higher $\mathrm{k}$-values with respect to vanadinite (e.g. Fig. 5a). EXAFS fitting results for the Z10-G-60C and Q10-G-136D series show similar V environments, where $\mathrm{r}, \mathrm{n}$, and $\sigma^{2}$, range from 1.66 to $1.69 \AA$, 3.9 to 4.6 atoms and 0.0022 to $0.0028 \AA^{2}$, respectively (Table 3 ). The EXAFS for the glasses follow the XANES trends above, where the average $\mathrm{V}$ environments in most glasses are similar to $\mathrm{VO}_{4}$ tetrahedra in vanadinite. (Fig. $5 \mathrm{a}-\mathrm{d}$ ). Therefore, $\mathrm{V}$ is present mostly within $\mathrm{V}^{5+} \mathrm{O}_{4}$ tetrahedra in these two glass series, as seen earlier for other borosilicate glasses [2].

However, the EXAFS data for the DWV-G-123B series glasses have more extreme differences with respect to vanadinite (Fig. $5 \mathrm{c}$ and d). The RE2 (60 min), RE4 (120 min), and RE10 (390 min) glass V EXAFS amplitudes are the most damped of all glasses measured, while the fitting results have the smallest $\mathrm{E}_{0}$ values, shortest $\mathrm{V}-\mathrm{O}$ distances, and smallest coordination numbers of all glasses investigated (Tables 3 and 4). This difference is due to the mixed $\mathrm{V}$ sites in these glasses, as shown from the XANES fitting, where RE2 glass has the largest $\mathrm{V}^{4+} \mathrm{O}_{5}$ population of any glass studied here. The damped EXAFS oscillations can be explained by the differences between the $\mathrm{k}^{2} \chi(\mathrm{k})$ data for vanadinite $\left(\mathrm{V}^{5+} \mathrm{O}_{4}\right)$ and cavansite $\left(\mathrm{V}^{4+} \mathrm{O}_{5}\right)$, where EXAFS oscillations are out-of-phase with respect to each other (Fig. 4a). A simple analysis routine was followed where the $\mathrm{k}^{2} \chi(\mathrm{k})$ data for vanadinite and cavansite were weighted and added together according to proportions dictated from the XANES fitting for the RE2, RE4, and RE10 glasses; these synthesized $\mathrm{k}^{2} \chi(\mathrm{k})$ data roughly describe the trends in the $\mathrm{k}^{2} \chi(\mathrm{k})$ data for the three glasses (e.g., Fig. 5e).

\subsection{Chromium EXAFS}

The $\mathrm{Cr}$ EXAFS for the standards crocoite $\left(\mathrm{Cr}^{6+} \mathrm{O}_{4}\right)$ and uvarovite $\left(\mathrm{Cr}^{3+} \mathrm{O}_{6}\right)$ also have oscillations out-of-phase with respect to each other (Fig. 6a). The corresponding RDFs of these standards show shifts of the nearest-neighbor peak that reflect the different average $\mathrm{Cr}-\mathrm{O}$ nearest-neighbor distances in these structures [12,13] (Fig. 6b). EXAFS fitting results for these standards (Table 5) are in reasonable agreement with parameters determined from crystal structure refinements.

Cr EXAFS data were collected and analyzed for Z10-G-60C parent glass, Z10-G-60CRE6 glass (180 min of bubbling), and Q10-G-136D parent glass (Fig. 6a). Similar to the XANES data, substantial differences are observed in the EXAFS of these glasses. According to $\mathrm{Cr}$ XANES analyses, Z10-G-60C glass contains the most oxidized $\mathrm{Cr}$ distribution of the three glasses measured and, correspondingly, the $\mathrm{k}^{2} \chi(\mathrm{k})$ data and partial RDF are similar to crocoite (Fig. 6a and b), indicating $\mathrm{Cr}^{6+} \mathrm{O}_{4}$ tetrahedra as the dominant $\mathrm{Cr}$-environment in this glass. The $\mathrm{k}^{2} \chi(\mathrm{k})$ data for Z10-G-60CRE6 glass show more EXAFS oscillations that are considerably damped compared with the parent glass (Fig. 6a), while the RDF has partially resolved nearest-neighbor peaks near 1.2 and $1.65 \AA$ A. These peaks likely correspond to the $\mathrm{CrO}_{4}$ tetrahedral nearest-neighbor peak for crocoite and the $\mathrm{Cr}^{3+} \mathrm{O}_{6}$ octahedral nearest-neighbor peak for uvarovite and indicate a mixture of $\mathrm{Cr}$ sites, with the minority being $\mathrm{Cr}$ tetrahedra.

The mixed $\mathrm{Cr}$-site EXAFS model reasonably fit the data for all three glasses (Table 6, and Fig. 6c). The analysis results determined $\mathrm{Cr}-\mathrm{O}$ bond distances typical of tetrahedral $\mathrm{CrO}_{4}$ and octahedral $\mathrm{CrO}_{6}$ (Table 5), where the reduced $\mathrm{Cr}$ percentages from XANES basically track parameter $\mathbf{b}$ (octahedral fraction of all $\mathrm{Cr}$-sites) from the EXAFS fitting.

Overall, the Cr EXAFS tetrahedral and octahedral two-site findings support the model used for Cr XANES, and indicates that this simple $\mathrm{Cr}^{3+} \mathrm{O}_{6}$ and $\mathrm{Cr}^{6+} \mathrm{O}_{4}$ site population model is a plausible description of the $\mathrm{Cr}$ distributions within the Z10-G-60CRE6 glass. From a $\mathrm{Cr}$ valence stability point-of-view, the above model is also plausible for $\mathrm{Cr}$ in

Table 4

First shell V-O fitting EXAFS results for the Na-poor DWV-G-123B glasses, from most oxidizing to most reducing synthesis conditions. $\mathrm{V}^{4+} /\left(\mathrm{V}^{5+}+\mathrm{V}^{4+}\right)$ are from the $\mathrm{XANES}$ analyses. Conventions in Table 2 are followed.

\begin{tabular}{|c|c|c|c|c|c|c|}
\hline Glass & $\mathrm{V}^{4+} /\left(\mathrm{V}^{5+} \pm \mathrm{V}^{4+}\right)$ & r-factor & $\mathrm{E}_{0}(\mathrm{eV})$ & $r(\AA)$ & $\mathrm{n}$ (atoms) & $\sigma^{2}\left(\AA^{2}\right)$ \\
\hline Parent glass & $15(2) \%$ & 0.043 & $6.3(3.9)$ & $1.71(0.03)$ & $4.1(0.8)$ & $0.0027(0.0029)$ \\
\hline RE2 (60 min) & $34(2)$ & 0.005 & $-2.8(1.6)$ & $1.63(0.01)$ & $3.4(0.2)$ & $0.0029(0.0009)$ \\
\hline RE4 (120 min) & $26(2)$ & 0.019 & $1.7(2.7)$ & $1.67(0.02)$ & $3.4(0.4)$ & $0.0025(0.0017)$ \\
\hline RE6 (180 min) & $16(2)$ & 0.020 & $1.8(2.7)$ & $1.66(0.02)$ & $3.7(0.5)$ & $0.0029(0.0019)$ \\
\hline RE8 (210 min) & $16(3)$ & 0.024 & $0.6(3.0)$ & $1.66(0.02)$ & $4.1(0.6)$ & $0.0028(0.0021)$ \\
\hline RE10 (390 min) & $21(2)$ & 0.019 & $-1.4(2.8)$ & $1.64(0.02)$ & $3.7(0.5)$ & $0.0031(0.0019)$ \\
\hline
\end{tabular}


a

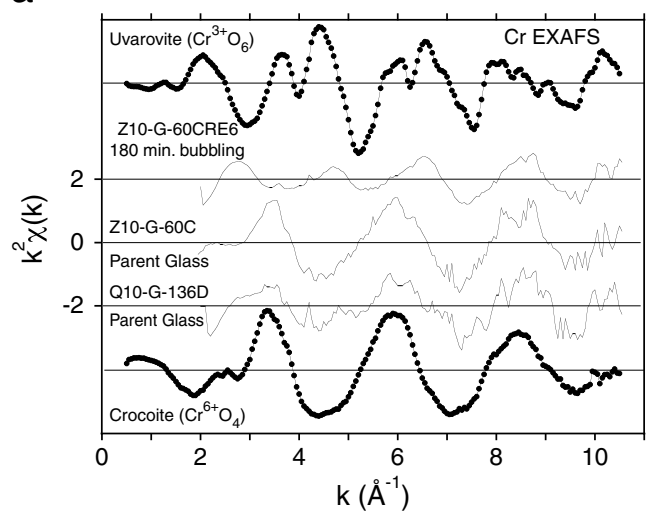

b

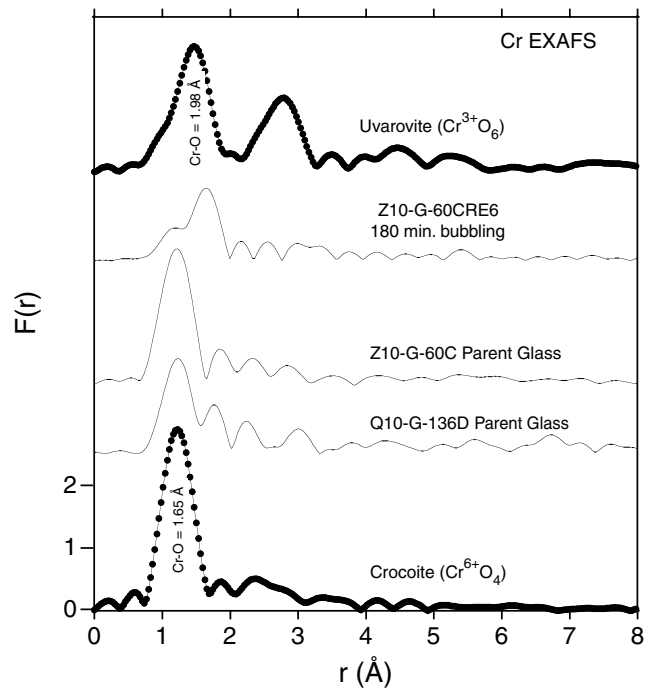

C
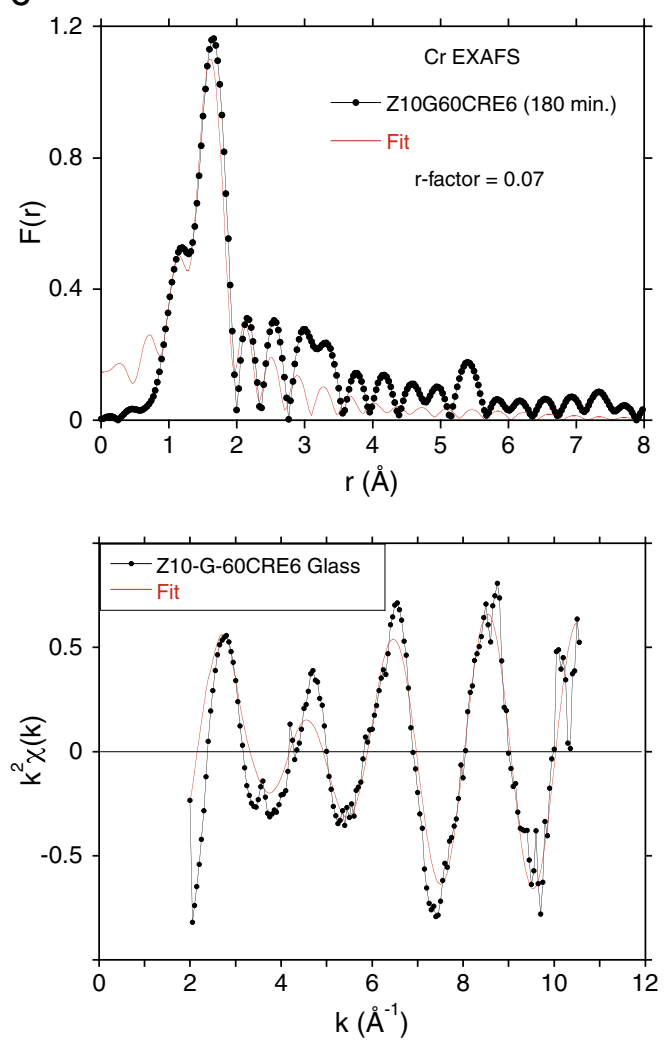

silicates because the $6+$ and $3+$ valence states are more favored under conditions that are not extremely reducing [17].

\subsection{Vanadium, chromium, and iron redox behavior in borosilicate glasses}

The three redox glass series investigated show different $\mathrm{V}$ and $\mathrm{Cr}$ valence behaviors depending on Na-content. The Na-rich Q10-G-136D and Z10-G-60C glass series show little change in the $\mathrm{V}$ valence distributions and large changes in the $\mathrm{Cr}$ valence distributions as bubbling time increases (Fig. 3a and b). However, the Na-poor DWV-G123B glass series behaves differently (Fig. 3c). DWV-G-123BRE2 glass (60 min of bubbling) has the most reduced $V$ valence distribution (near $33 \% \mathrm{~V}^{4+}$ ) of all glasses measured. As the bubbling time increases, $\mathrm{Cr}$ in these glasses become more reduced, with no evidence of $\mathrm{Cr}^{6+}$ and increasing evidence of $\mathrm{Cr}^{2+}$. Simultaneously, $\mathrm{V}$ becomes more oxidized, returning to the level of the parent glass. Mössbauer results for $\mathrm{Fe}$ roughly follow the $\mathrm{V}$ trend for the DWV-G-123BRE2 and DWV-G123BRE10 (390 min of bubbling) glasses, as $\mathrm{Fe}^{2+} / \mathrm{Fe}_{\text {total }}$ is $47 \%$ and $31 \%$, respectively, while $\mathrm{V}^{4+} / \mathrm{N}_{\text {ttotal }}$ is $35 \%$ and $22 \%$, respectively (Fig. 3c). Due to the increasing amounts of $\mathrm{Cr}^{2+}$ and the vanishing $\mathrm{Cr}^{6+}$ populations in the DWV-G-123B glasses, as the series becomes more reduced, the $\mathrm{Cr}$ valence details cannot be quantified by the XANES fitting procedure used here, other than indicating $\mathrm{Cr}^{3+} /\left(\mathrm{Cr}^{3+}+\mathrm{Cr}^{6+}\right)=100 \%$.

Redox studies of various cations in silicate glasses were performed by Schreiber [17], where $\mathrm{V}$ and $\mathrm{Cr}$ valence ratios were determined for a range of oxygen fugacities. The SRL-131 and ADA glasses in Schreiber's work are considerably more silica-rich and have other significant chemical differences compared with those glasses studied here; however, simple $\mathrm{V}$ and $\mathrm{Cr}$ valence trend comparisons can be made by using $\mathrm{Na}_{2} \mathrm{O} / \mathrm{SiO}_{2}$ wt.\% ratios. In this case, $\mathrm{SRL}-131$ and $\mathrm{ADA}$ glasses, where $\mathrm{Na}_{2} \mathrm{O} / \mathrm{SiO}_{2}$ is 0.31 and 0.10 , respectively, can be compared with Q10-G-136D and DWV-G-136B glasses, where $\mathrm{Na}_{2} \mathrm{O} / \mathrm{SiO}_{2}$ is 0.39 and 0.24 , respectively. For SRL-131 glass at $\log \left(\mathrm{fO}_{2}\right) \approx-8$, equivalent to the most reducing synthesis conditions for the glasses investigated here, $\mathrm{Cr}^{2+} / \mathrm{Cr}^{3+}$ and $\mathrm{V}^{4+} / \mathrm{V}^{5+}$ are approximately 0.03 and 0.5 , respectively, while $\mathrm{Cr}^{3+} / \mathrm{Cr}^{6+} \gg 0.99$. Schreiber's findings suggest that in the most reduced case, Q10-G-136D glass would have $\mathrm{V}^{4+}$ / $\mathrm{V}_{\text {total }} \approx 0.33$ with the majority of $\mathrm{Cr}$ as $\mathrm{Cr}^{3+}$. XANES fitting results (Fig. 3b) indicate that the Q10-G-136D glasses have more oxidized $V$ than this limit, but generally follow Schreiber's $\mathrm{Cr}$ estimate. For ADA glass synthesized at $\log \left(\mathrm{fO}_{2}\right) \approx-8, \mathrm{Cr}^{2+} \approx 0.07$ and $\mathrm{Cr}^{3+} \approx 0.93\left(\mathrm{Cr}^{2+} / \mathrm{Cr}^{3+}\right.$ is approximately 0.08 ) which is more reduced than SRL-131 glass. This trend in Schreiber's glasses roughly parallels the finding that the DWV-G-123B glasses have more reduced $\mathrm{Cr}$ than the equivalent Q10-G-136D glasses. Schreiber's findings for ADA glass suggest that small amounts of $\mathrm{Cr}^{2+}$ would be expected in the most reduced DWV-G-123B glass, whereas the XANES evidence shows that $\mathrm{Cr}^{2+}$ populations are possible in any of the DWV-G-123B glasses, where the melts were exposed to bubbling.

The observed $\mathrm{V}$ and $\mathrm{Cr}$ XAS trends and the Fe Mössbauer results for the $\mathrm{Na}_{2} \mathrm{O}$-poor DWV-G-123B glasses as bubbling time increases are suggestive of redox coupling reactions involving electron donations from $\mathrm{V}$ to $\mathrm{Cr}$ and from Fe to $\mathrm{Cr}$ where: (1) $\mathrm{Cr}^{3+}+\mathrm{V}^{4+} \rightarrow \mathrm{Cr}^{2+}+\mathrm{V}^{5+}$, and (2) $\mathrm{Cr}^{3+}+\mathrm{Fe}^{2+} \rightarrow \mathrm{Cr}^{2+}+\mathrm{Fe}^{3+}$. Reaction (2) was observed by measuring the $\mathrm{Cr}^{2+} / \mathrm{Cr}^{3+}$ ratio in Fe-bearing melts [18].

Further work on the DWV-G-123B series is under way to better characterize the $\mathrm{Cr}$ valence distributions. It may be possible to obtain additional valence detail from the XANES fitting of these spectra using a crystalline $\mathrm{Cr}^{2+}$-silicate standard similar to those presented in Refs. $[19,20]$. Cr EXAFS of the more reduced glasses in this series may also provide $\mathrm{Cr}$ coordination information indicative of Jahn-Teller distorted tetrahedral [21] or octahedral environments [22] associated

Fig. 6. a. $\mathrm{Cr} \mathrm{k}^{2} \chi(\mathrm{k})$ for the $\mathrm{Cr}^{6+}$ and $\mathrm{Cr}^{3+}$ standards and three $\mathrm{Cr}$-rich glasses. b. Cr partial RDFs for the $\mathrm{Cr}^{6+}$ and $\mathrm{Cr}^{3+}$ standards and three $\mathrm{Cr}$-rich glasses. c. Cr EXAFS fitting results for Z10-G-60CRE6 glass, where Cr XANES fitting indicates $0.34\left(\mathrm{Cr}^{6+} \mathrm{O}_{4}\right)+0.66\left(\mathrm{Cr}^{3+} \mathrm{O}_{6}\right)$. Final EXAFS fitting parameters are listed in Table 6. 
Table 5

First shell $\mathrm{Cr}-\mathrm{O}$ fitting EXAFS results for the standards, using $\mathrm{s}_{0}^{2}=0.80$. $\mathrm{E}_{0}$ values are from $5989 \mathrm{eV}$. Uncertainties are listed in parentheses.

\begin{tabular}{lllll}
\hline Sample & r-factor & $\mathrm{E}_{0}(\mathrm{eV})$ & $\mathrm{r}(\AA)$ & $\mathrm{n}(\mathrm{atoms})$ \\
\hline Crocoite & 0.069 & 13.4 & $1.65(0.01)$ & $3.5(0.4)$ \\
$\quad$ Actual [12] & & & 1.66 & $\sigma^{2}\left(\AA^{2}\right)$ \\
Uvarovite & 0.077 & -0.9 & $1.98(0.01)$ & $0.0001(0.0013)$ \\
$\quad$ Actual [13] & & & 1.98 & $5.3(0.6)$ \\
\hline
\end{tabular}

Table 6

First shell $\mathrm{Cr}-\mathrm{O}$ fitting EXAFS results for three representative glasses, from oxidized to more reduced synthesis conditions, using $\mathrm{s}_{0}^{2}=0.80$ and $\mathrm{E}_{0}=13.4 \mathrm{eV}(\mathrm{from} 5989 \mathrm{eV}) . \mathrm{Cr}^{3+} /$ $\left(\mathrm{Cr}^{3+}+\mathrm{Cr}^{6+}\right)$ values are from the XANES analyses. Two-site fitting was implemented assuming tetrahedral $\mathrm{CrO}_{4}(\mathrm{n}=4)$ and octahedral $\mathrm{CrO}_{6}(\mathrm{n}=6)$; $\mathbf{a}$ is the fraction of tetrahedral $\mathrm{Cr}$; and $\mathbf{b}$ the fraction of octahedral $\mathrm{Cr}$. Uncertainties are listed in parentheses; (c)=constrained fitting parameter.

\begin{tabular}{|c|c|c|c|c|c|c|c|c|}
\hline \multirow[t]{2}{*}{ Glass } & \multirow[t]{2}{*}{$\mathrm{Cr}^{3+} /\left(\mathrm{Cr}^{3+} \pm \mathrm{Cr}^{6+}\right)$} & \multirow[t]{2}{*}{$r$-factor } & \multicolumn{3}{|c|}{ Tetrahedral $\mathrm{CrO}_{4}$} & \multicolumn{3}{|c|}{ Octahedral $\mathrm{CrO}_{6}$} \\
\hline & & & $\mathrm{r}(\AA)$ & $\mathrm{a}$ & $\sigma^{2}\left(\AA^{2}\right)$ & $\mathrm{r}(\AA)$ & $\mathrm{b}$ & $\sigma^{2}\left(\AA^{2}\right)$ \\
\hline Z10-G-60C parent glass & $16(0.01) \%$ & 0.105 & $1.64(0.01)$ & $0.83(0.10)$ & $0.0012(0.0016)$ & $2.01(0.05)$ & $0.17(0.09)$ & $0.0007(0.0073)$ \\
\hline Z10-G-60C RE6 (180 min.) & $66(0.01)$ & 0.072 & $1.64(0.01)$ & $0.49(0.08)$ & $0.0038(0.0023)$ & $1.99(0.01)$ & $0.51(0.05)$ & $0.0002(0.0012)$ \\
\hline Q10-G-136D parent glass & $34(0.01)$ & 0.085 & $1.64(0.01)$ & $0.70(0.10)$ & $0.0007(\mathrm{c})$ & $1.99(0.02)$ & $0.30(0.10)$ & $0.0015(c)$ \\
\hline
\end{tabular}

with $\mathrm{Cr}^{2+}$. Optical absorption as well as electron spin resonance measurements of these glasses may provide more specific $\mathrm{Cr}$ valence information than Cr XAS.

\section{Conclusions}

$\mathrm{X}$-ray absorption spectra were collected on three redox glass series to characterize the $\mathrm{V}$ - and $\mathrm{Cr}$-environments in borosilicate LAW glass formulations. XAS indicates that $\mathrm{V}$ and $\mathrm{Cr}$ behaviors are significantly different as the glasses become more reduced with increasing $\mathrm{CO}-\mathrm{CO}_{2}$ bubbling times of the corresponding melts.

In the two Na-rich glass series investigated, the $\mathrm{V}^{5+} \mathrm{O}_{4}+\mathrm{V}^{4+} \mathrm{O}_{5}$ model, and the $\mathrm{Cr}^{6+} \mathrm{O}_{4}+\mathrm{Cr}^{3+} \mathrm{O}_{6}$ model describe the $\mathrm{V}$ and $\mathrm{Cr}$ environments, respectively. $\mathrm{V}$ XANES and EXAFS analyses show that the $\mathrm{V}$ distribution consisting of predominantly oxidized $\mathrm{V}^{5+} \mathrm{O}_{4}$ with minor $\mathrm{V}^{4+} \mathrm{O}_{5}$ populations in the parent glasses retains this mostly oxidized distribution throughout each redox series, where $\mathrm{V}^{4+} / N_{\text {total }}$ ranges from 6 to $15 \%$. In contrast, Cr XANES and EXAFS analysis results show that as bubbling time increases, $\mathrm{Cr}$ becomes steadily more reduced by having larger $\mathrm{Cr}^{3+} \mathrm{O}_{6}$ populations throughout these two glass series, where $\mathrm{Cr}^{3+} / \mathrm{Cr}_{\text {total }}$ ranges from 15 to $95 \%$.

In the Na-poor glass series, more reduced $\mathrm{Cr}$ distributions are observed, including $\mathrm{Cr}^{2+}$ populations that may be coupled to $\mathrm{V}^{4+}$ oxidation to $\mathrm{V}^{5+}$. After initial bubbling, $\mathrm{V}^{4+} / \mathrm{V}_{\text {total }}$ ratios increase from $15 \%$ in the parent glass to a maximum near $35 \%$. However, as bubbling times increase, $\mathrm{V}^{4+} / \mathrm{V}_{\text {total }}$ ratios decrease to near the level of the parent glass. At the same time, $\mathrm{Cr}^{3+} /\left(\mathrm{Cr}^{3+}+\mathrm{Cr}^{6+}\right)$ values start at $85 \%$ for the parent glass and increase to $100 \%$, with no evidence of $\mathrm{Cr}^{6+}$, while $\mathrm{Cr}^{2+}$ populations appear to increase. This behavior may indicate redox coupling between $\mathrm{V}$ and $\mathrm{Cr}$ as well as between $\mathrm{Fe}$ and $\mathrm{Cr}$, where $\mathrm{Cr}$ continues to be reduced to $\mathrm{Cr}^{2+}$ at the expense of $\mathrm{V}^{4+}$ and $\mathrm{Fe}^{2+}$.

\section{Acknowledgments}

We thank J.E. Post and P. Pohwat (Mineral Sciences Department, National Museum of Natural History, Smithsonian Institution) for supplying the vanadinite, cavansite, roscoelite, crocoite, and uvarovite standards. We also thank Johnny P. Kirkland (SFA, Inc.) for his assistance on NSLS Beam Line X23B. This work was supported in part by the U.S. Department of Energy (DOE) Office of River Protection through Energy Solutions, Inc.

\section{References}

[1] I.S. Muller, H. Gan, D. McKeown, W. Kot, I. Joseph, I.L. Pegg, Final Report VSL09R1510-1: “ORP Glass High Temperature Testing HLW Glass Crystallization and LAW Glass Redox" Vitreous State Laboratory, The Catholic University of America, Washington, DC, 2009

[2] D.A. McKeown, I.S. Muller, K.S. Matlack, I.L. Pegg, X-ray absorption studies of vanadium valence and local environment in borosilicate waste glasses using vanadium sulfide, silicate, and oxide standards, J. Non-Cryst. Solids 298 (2002) 160.

[3] G. Giuli, E. Paris, J. Mungall, C. Romano, D. Dingwell, V oxidation state and coordination number in silicate glasses by XAS, Am. Mineralog. 89 (2004) 1640-1646.

[4] O. Villain, G. Calas, L. Galoisy, L. Cormier, J.-L. Hazemann, XANES determination of chromium oxidation states in glasses: comparison with optical absorption spectroscopy, J. Am. Ceram. Soc. 90 (2007) 3578.

[5] P. Hrma, J.D. Vienna, B.K. Wilson, T.J. Plainsted, S.M. Heald, Chromium phase behavior in a multi-component borosilicate glass melt, J. Non-Cryst. Solids 352 (2006) 2114.

[6] S. Bajt, S.B. Clark, S.R. Sutton, M.L. Rivers, J.V. Smith, Synchrotron X-ray microprobe determination of chromate content using X-ray absorption nearedge structure, Anal. Chem. 65 (1993) 1800.

[7] A.J. Berry, H.St.C. O'Neill, D.R. Scott, G.J. Foran, J.M.G. Shelley, The effect of composition on $\mathrm{Cr}^{2+} / \mathrm{Cr}^{3+}$ in silicate melts, Am. Mineralog. 91 (2006) 1901.

[8] A.J. Berry, H.St.C. O'Neill, G.J. Foran, Electron exchange between V and Cr in silicate glasses, Geochim. Cosmochim. Acta 70 (2006) A48.

[9] Y. Dai, J. Hugnes, Crystal structure refinements of vanadinite and pyromorphite, Canad. Min. 27 (1989) 189.

[10] H.T. Evans, The crystal structures of cavansite and pentagonite, Am. Mineralog. 58 (1973) 412.

[11] E.W. Heinrich, A.A. Levinson, Studies in the mica group; $x$-ray data on roscoelite and barium-muscovite, Amer. J. Sci. 253 (1955) 39.

[12] S. Quareni, R. De Pieri, A three-dimensional refinement of the structure of crocoite, $\mathrm{PbCrO}_{4}$, Acta Crystallogr. 19 (1965) 287.

[13] G.A. Novak, G.V. Gibbs, The crystal chemistry of the silicate garnets, Am. Mineralog. 56 (1971) 791

[14] K.D. Jayasuriya, H.C. O'Neill, A.J. Berry, S.J. Campbell, A Mössbauer study of the oxidation state of iron in silicate melts, Am. Mineralog. 89 (2004) 1597.

[15] M. Newville, IFEFFIT: interactive XAFS analysis and FEFF fitting Further information about IFEFFIT can be obtained at:, J. Synchrotron Radiat. 8 (2001) 322 http://cars9.uchicago.edu/ifeffit/.

[16] D.E. Sayers, B.A. Bunker, in: D.C. Kroningsberger, R. Prins (Eds.), X-ray Absorption Principles, Applications, Techniques of EXAFS, SEXAFS, and XANES, Wiley, New York, 1988, p. 211, Ch. 6.

[17] H.D. Schreiber, An electrochemical series of redox couples in silicate melts: a review and applications to geochemistry, J. Geophys. Res. 92 (1987) 9225.

[18] A.J. Berry, J.M.G. Shelley, G.J. Foran, H.S.C. O'Neill, D.R. Scott, A furnace design for XANES spectroscopy of silicate melts under controlled oxygen fugacities and temperatures to $1773 \mathrm{~K}$, J. Synchrotron Radiat. 10 (2003) 332.

[19] W.A. Dollase, F. Seifert, H. St, C. O'Neill, Structure of $\mathrm{Cr}_{2} \mathrm{SiO}_{4}$ and possible metalmetal interactions in crystal and melt, Phys. Chem. Miner. 21 (1994) 104.

[20] H.L. Belsky, G.R. Rossman, C.T. Prewitt, T. Gasparik, Crystal structure and optical spectroscopy ( 300 to $2200 \mathrm{~nm}$ ) of $\mathrm{CaCrSi}_{4} \mathrm{O}_{10}$, Am. Mineralog. 69 (1984) 771.

[21] H.St.C. O'Neill, A.J. Berry, Activity coefficients at low dilution of $\mathrm{CrO}, \mathrm{NiO}$ and $\mathrm{CoO}$ in melts in the system $\mathrm{CaO}-\mathrm{MgO}-\mathrm{Al}_{2} \mathrm{O}_{3}-\mathrm{SiO}_{2}$ at $1400{ }^{\circ} \mathrm{C}$ : using the thermodynamic behaviour of transition metal oxides in silicate melts to probe their structure, Chem. Geol. 231 (2006) 77.

[22] A.J. Berry, H.St.C. O'Neill, A XANES determination of the oxidation state of chromium in silicate glasses, Am. Mineralog. 89 (2004) 790. 